\title{
Plasma cells in caseous necrosis of nerves in leprosy
}

\author{
N H ANTIA \& N F MISTRY \\ The Foundation for Medical Research, 84-A, R.G. Thadani Marg, \\ Worli, Bombay 400018, India
}

Accepted for publication 1 May 1985

\begin{abstract}
Summary A large number of plasma cells were identified by direct immunoperoxidase staining in caseous nerve abscesses of all 14 borderline, borderline tuberculoid and polar tuberculoid leprosy patients. The specificity of the secreted antibody appeared to be directed against mycobacterial antigenic determinants. This hitherto unreported observation stresses the role of local humoral immune mechanisms in the pathogenesis of the tuberculoid form of leprosy.
\end{abstract}

\section{Introduction}

Caseous nerve abscesses in earlier reports ${ }^{1}$ were mainly associated with the resistant tuberculoid form of leprosy, or primary neuritis; both groups being classically associated with active epithelioid cell granulomas surrounded by a cuff of lymphocytes and a marked absence of acid-fast bacilli. In such a state, humoral immunity was understood to play an insignificant role in the killing or expression of DTH reactions to Mycobacterium leprae, a belief having many adherents even today.

Since 1980, caseous nerve abscesses were observed by us in 14 leprosy patients exhibiting polar tuberculoid, borderline tuberculoid, or borderline form of the disease but with no clinical signs of lepra reactions. We report here on the general morphology and inflammatory cell pattern in caseated nerve abscesses, stressing particularly our consistent observation of a large number of plasma cells in all of the 14 patients exhibiting caseous nerve abscesses.

\section{Methods}

The treatment status of the 14 patients varied from untreated to a duration of 6 years. The nerves from which the biopsies were obtained included 6 ulnar nerves, 
2 index branches of the radial cutaneous nerves, 2 greater auricular and median nerves and 1 each of sural and intercostal nerves.

The biopsies were obtained during surgery for treatment and evacuation of abscess(es). A fine wedge-shaped biopsy was taken from the wall of the abscess before evacuation, fixed in Formol-Zenker and processed routinely for light microscopy. The sections were stained by the routine Trichrome Fite-Farraco (TRIFF) and Fite methods, the latter being imperative for visualization of acid-fast bacilli.

The presence of plasma cells was demonstrated by direct application of anti-human IgG or IgM $(1: 20)$ conjugated to peroxidase (DAKOPATTS). The reaction was developed using 3,3'diaminobenzidene tetrahydrochloride (SIGMA), with Harris' haematoxylin as a counter stain.

Attempts to demonstrate mycobacterial sub-cellular antigen fractions were made using anti-BCG (1:50, DAKOPATTS) in the peroxidase-anti peroxidase (PAP) system. ${ }^{2}$

A portion of the biopsy from 3 BT patients was teased and chopped. Both tissues as well as extracted cells were cultured in MEM for a period of $48 \mathrm{hr}$. The supernatants were collected and used for running against standard human immunoglobulin preparation $(\operatorname{IgG}+\operatorname{IgM}+\operatorname{Ig} \mathrm{A}$, WHO) in a standard continuous buffer SDS-PAGE (concentration of separating gel $10 \%$ ) to assure the presence of secreted antibody.

The supernatants were also applied in the troughs in a standard immunoelectrophoretic assay and run against homogenized nerve extracts of two normal Swiss white mouse sciatic nerves or $M$. leprae sonicates placed in the wells.

\section{Observations}

The abscesses were observed chiefly in the major nerve trunks but they also occurred in cutaneous nerves, lying within the nerve itself or breaking through the epineurium to form a collar-stud extension. The abscesses were visualized as a series of one or more nodular swellings in the nerve which on longitudinal epineurotomy were seen generally to lie in a linear fashion along one or two nerve fascicles.

A typical histological picture of the abscess wall is demonstrated in Figures 1 and 2. The lesions were generally restricted to one or two funicles that were grossly enlarged and showed dense deposits of collagen in the interfunicular region, in the perineurium and in the sub-perineurial endoneurial area. Except for the thickened perineurium, there was total destruction of the normal structure of the funicle.

The centre of the amorphous caseous mass consisted largely of degenerating pyknotic nuclei without a defined cell wall. Just immediate to the caseous material was a layer of large mononuclear cells of the epitheliod variety often fusing to 


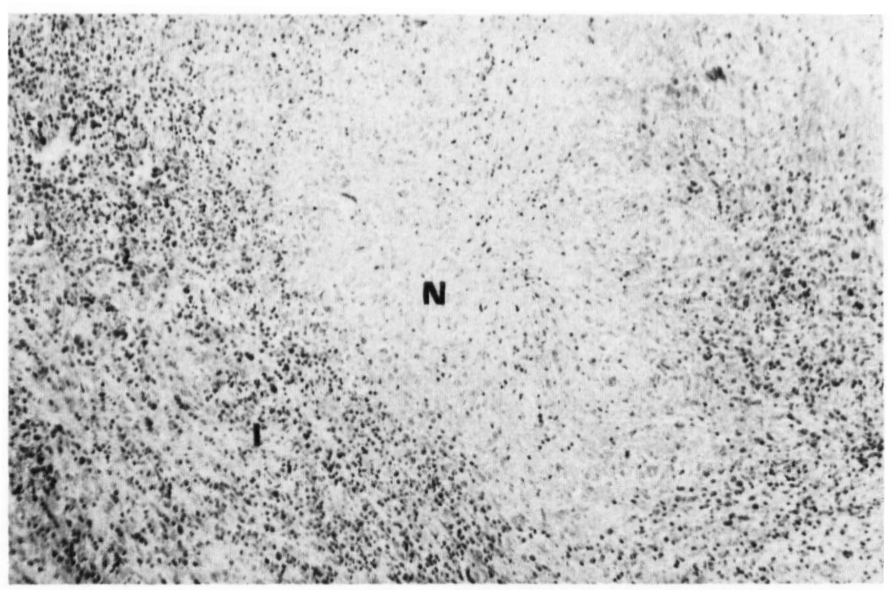

Figure 1. T.S. of greater auricular nerve of BT patient showing central necrotic mass $(\mathrm{N})$ surrounded by a dense collar of inflammatory cells $(\mathrm{I})(\times 372)$.

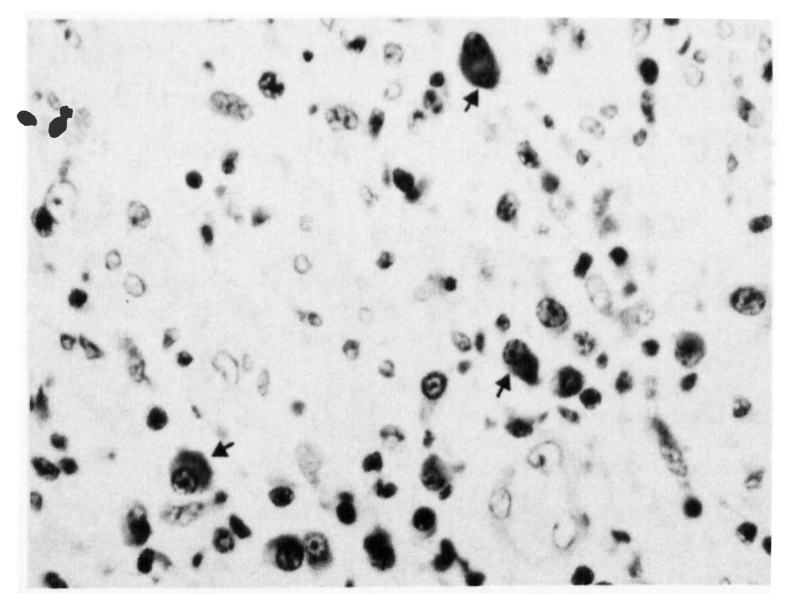

Figure 2. T.S. of greater auricular nerve of the same BT patient. A magnified view of inflammatory cell collar demonstrating abundance of plasma cells $(\rightarrow$.$) These were identified by localization of$ peroxidase conjugated anti-human IgG/M. Counter stain Harris haematoxylin $(\times 948)$.

form giant cells. These cells seemed positive for collagenase activity. The inner wall of this intermediate layer appeared synonymous with the outer wall of the caseous mass and showed the transition of cells from the normal to the degenerated state.

Towards the wall of the caseous funicle, these cells were joined by a large number of plasma cells, mainly in clusters, generally restricted to the cellular layer but sometimes within the necrotic mass. The plasma cells extended as far as the perineurial cell layers in association with epitheliod cells and moderate numbers of lymphocytes. This sub-perineurial zone also displayed enhanced vascularity 
and it was possible to observe migration of plasma cells and very occasionally polymorphonuclear cells through these blood vessels. Very few PMNs if any, were noted in the cellular layers. The perineurium was thickened and showed the presence of active perineurial cells. It was interrupted at places by epitheliod cells, plasma cells and moderate numbers of lymphocytes. No acid-fast bacilli could be demonstrated within or around the caseous mass.

The repeated presence of plasma cells was confirmed by their typical morphology during routine staining and by direct application of HRP conjugated anti-human IgG or IgM (Figure 2). Dense Ig staining was obtained intracellularly in and around the caseous mass. The plasma cells around the caseous mass were seen to secrete predominantly IgG and. IgM. However, the caseous mass itself stained only for $\operatorname{IgM}$, a feature consistent with caseous lymph nodes in tuberculosis (Ridley, personal communication).

Precipiting lines were consistently observed when these supernatants were run against sonicated $M$. leprae in an immunoelectrophoretic system. No reaction was noted against homogenized mouse sciatic nerve. This feature correlated with the finding of granular antigen deposit within epitheliod-like cells in the subperineurial zone in these nerves as detected by anti-BCG antibody via the PAP system. Therefore despite the striking absence of detectable integral acid-fast bacilli in these biopsies, the locally synthesized antibody appeared to be directed against bacterial antigens.

\section{Discussion}

The singular feature hitherto unreported is the repeated presence of a large number of Ig secreting plasma cells in the caseous necrotic mass. Such a lesion is not, as previously thought, restricted to polar tuberculoid leprosy, and can occur, as shown here in the borderline groups of patients also with no clinical symptoms of lepra reactions. The inflammatory cell pattern is not of the classical CMI granuloma, is more compatible with a borderline type of response and unlike the liquefied abscesses of ENL lesions is devoid of PMN's as well as acid fast bacilli. ${ }^{3}$ The formation of such a lesion probably has its basis in a critical proportion of antigen, antibody and $\mathrm{CMI}{ }^{4}$

The specificity of these antibodies secreted in the caseous mass, like those synthesized in $M$. leprae infected skins, ${ }^{5}$ are directed against bacterial determinants. Whether these antigens have been liberated because of an initial cell-mediated immune reaction remains speculative but there is some evidence to state that plasma cells could predispose to caseous necrosis, since in two patients, these cells were noted in large numbers in the precaseous stage.

We postulate on the basis of observations made in cutaneous leishmaniasis, that caseous necrosis may be associated with the killing (or clearance) of $\boldsymbol{M}$. leprae at localized sites. Leishmania amastigotes were seen to be most rapidly 
eliminated by focal necrosis as opposed to compact granulomatous formations that paradoxically enhanced bacterial growth. ${ }^{6}$

In summation this report underlines the strong association between local humoral immune mechanisms and the paucibacillary form of leprosy.

\section{References}

1 Sato D. Nerve abscesses in lepromatous leprosy: Report of a case, with a review of reports of nerve abscesses in Japan. Int $J$ Lep, 1956; 24: 408.

${ }^{2}$ Steinberger LA, Hardy P, Cuculis T, Meyer H. The unlabelled antibody enzyme method of immunohistochemistry. Preparation and properties of soluble antigen-antibody complex (horseradish peroxidase-antihorseradish peroxidase) and its use in the identification of spirochetes. J Histochem Cytochem, 1969; 19: 682.

${ }^{3}$ Malaviya G, Mukherjee A, Ramu, G. Nerve abscesses in lepromatous leprosy. Lep India, 1982; 54: 123.

${ }^{4}$ Spector W, Heesom, N. The production of granulomata by antigen-antibody complexes. J. Path, 1969; 98: 3I.

5 Fat RFLMA. In vitro synthesis of anti-microbial antibodies in biopsies from skin lesions of leprosy patients. Infect \& Immun, 1980; 27: 297.

${ }^{6}$ Ridley D. The pathogenesis of cutaneous leishmaniasis. Trans Roy' Soc Trop Med and Hyg, 1979; 73: 150. 